\title{
Perceptions of risk for COVID-19 among individuals with chronic diseases and stakeholders in Central Appalachia
}

Manik Ahuja (1) ${ }^{1 凶}$, Hadii M. Mamudu', Florence M. Weierbach², Karilynn Dowling-McClay ${ }^{3}$, David W. Stewart ${ }^{3}$, Manul Awasthi ${ }^{1} \&$ Timir K. Paul ${ }^{4}$

Coronavirus disease 2019 (COVID-19) pandemic is rapidly evolving and is a serious public health threat worldwide. Timely and effective control of the pandemic is highly dependent on preventive approaches. Perception of risk is a major determinant of health behavior. The current study explores the association between actual risk and perceived risk for one's self, family/friends and friends, and community. A questionnaire was administered to participants in Central Appalachia $(n=102)$. The actual risk was based on the number of chronic conditions of the following conditions: hypertension, heart disease, cancer, diabetes, and chronic obstructive pulmonary disease. Participants were also queried about their perception of risk for COVID-19. Generalized Linear Models were used to independently evaluate the likelihood of perceived risk for one's: self, family/friends, and community, based on actual risk. Actual risk for COVID-19 was significantly associated with higher likelihood of higher perception of risk for one's self $(b=0.24 ; p=0.04)$, but not with one's family/friends $(b=0.05 ; p=0.68)$, or one's community $(b=0.14 ; p=0.16)$. No health insurance was negatively associated with perception of risk for self $(b=-0.59 ; p=0.04)$ and family/friends $(b=-0.92 ; p<0.001)$. Male gender $(b=-0.47 ; p=0.01$ ) was also negatively associated with perception of risk for family/friends. In conclusion, individuals' actual risk for COVID-19 is associated with their own perception of risk. This indicates that one's perception of risk for COVID-19 is greater for their own health compared to their family/friends or the community. Therefore, monitoring and following up with chronic disease patients and addressing their lack of awareness of risk to others is needed to prevent and curtail the spread of COVID-19.

\footnotetext{
${ }^{1}$ College of Public Health, East Tennessee State University, Johnson City, TN 37614, USA. ${ }^{2}$ College of Nursing, East Tennessee State University, Johnson City, TN 37614, USA. ${ }^{3}$ College of Pharmacy, East Tennessee State University, Johnson City, TN 37614, USA. ${ }^{4}$ Quillen College of Medicine, East Tennessee State University, Johnson City, TN 37614, USA.凶email: ahujam@etsu.edu
} 


\section{Introduction}

he recent outbreak of coronavirus disease 2019 (COVID19) pandemic has spread rapidly on a global scale, leading to a large number of hospitalizations and deaths worldwide (The Lancet, 2020; Weinberger et al., 2020). The pandemic has impacted the world significantly; while some areas are now recovering from it, others are just beginning to be affected (Jehi et al., 2020), and there is a resurgence in areas that appear to have spread the virus under control. COVID-19 is often accompanied by flu-like symptoms, acute respiratory distress syndrome, acute kidney injury, myocarditis, and organ failure (Tian et al., 2020; Yang et al., 2020). Those burdened with chronic diseases (e.g. cardiovascular disease, diabetes, cancer, asthma) are disproportionately impacted, and at a higher risk for hospitalizations, morbidity, and mortality (Bhatraju et al., 2020; Guan et al., $2020 \mathrm{a}, 2020 \mathrm{~b})$. As the number of hospitalization and deaths have continued to rise globally, it is becoming increasingly important to understand the perception of risk for COVID-19 (Bavel et al., 2020) and application of mitigation strategies such as hand washing, physical distancing, avoiding public places, wearing face masks, testing, and uptake of vaccination (Bish and Michie, 2010; Golestaneh et al., 2020).

Perception of risk is a major determinant of health behaviors (Schmälzle et al., 2017). According to theories of decisions about health behavior, people who perceive greater risks are more likely to engage in preventive behaviors (Fischhoff, 1995). As such, the perception of risk will likely inform the decisions of individuals to adhere to prevention and mitigation measures including decisions on vaccinations for COVID-19 to reduce risk (Bruine de Bruin and Bennett, 2020; Ibuka et al., 2010; Karlsson et al., 2021; Van Der Weerd et al., 2011). Additionally, because screening for diseases/risks facilitates early detection and treatment (Bauer et al., 2014) the perception of risks will likely inform the decision of individuals on whether to test for a disease. Behaviors and preventive measures during a pandemic are often guided by one's perceived risk and susceptibility to the disease (Iorfa et al., 2020; Irigoyen-Camacho et al., 2020; Lohan and Singh, 2019; O'Brien et al., 2021; Shahin and Hussien, 2020). Adoption of prevention and mitigation behaviors is of particular importance to prevent the spread of disease (Courtemanche et al., 2020; Nande et al., 2021). During a pandemic, perceived risks are observed through channels of communication, such as media, television, the internet, and in the community (Sandman, 1989). This situation could create discrepancies between the public's perception and scientific evidence, providing a rationale for research into perceptions of risk about COVID-19.

Prior studies have found an association with perceived risk and preventive behaviors for COVID-19. In a nationally representative survey from the United States (U.S.), Bruine and Bennett (2020) reported that those who perceived a higher risk reported 1.45 times higher odds of handwashing and also higher odds of avoiding crowds. In a global study, Dryhurst et al. (2020) reported that variability across cultures, individualistic worldviews, personal experience, prosocial values, and social amplification through friends and family were found to be significant in more than half of the countries examined (Dryhurst et al., 2020). Nevertheless, studies that specifically focus on vulnerable and underserved populations residing in rural areas of the U.S. do not exist, to the best of our knowledge. While a growing body of literature has examined the association between perceived risk and preventive behaviors (Ding et al., 2020; Zhong et al., 2020), to our knowledge no study has examined the gap between perceived risk and actual risk involving COVID-19. Additionally, there is a limited body of literature that focuses on perceived risks and COVID-19 among patients with chronic diseases and their stakeholders. It is well established that those who suffer from chronic diseases are at increased risk for adverse outcomes with COVID-19 and, as such, it is vital to focus on these populations, especially those residing in underserved rural areas in the U.S., including Central Appalachia.

It is important to consider perceived and actual risk separately, as they are two independent constructs. Perceived risk is an individual's subjective evaluation of their risk of an illness or an adverse outcome ("Encycl Behav Med" 2013). Actual risk encompasses risk factors such as age, demographics, health status, and other factors that increase or decrease risk. Therefore, guided by health promotion model, specifically the Health Belief Model (HBM), the current study aimed to investigate the differences between the perception of risk and actual risk using a regional sample from the U.S. Central Appalachia. This region is heavily burdened with a high prevalence of chronic diseases (Meacham et al., 2015; Shi et al., 2019; Zullig and Hendryx, 2011) and COVID-19-related consequences (Shah, 2020). As there is an abundance of misinformation regarding this disease, therefore we hypothesize that individuals' COVID-19 risk perceptions may not accurately reflect their actual risk.

\section{Methods}

Study setting and population. This study builds on a project funded by the Patient-Centered Outcomes Research Institute (PCORI) Engagement Award that developed a research agenda for cardiovascular diseases (CVD) in the Central Appalachian region, which comprises 228 contiguous and two non-contiguous counties in six states (Kentucky [KY], North Carolina [NC], Ohio $[\mathrm{OH}]$, Tennessee [TN], Virginia [VA], and West Virginia [WV]). Residents of this region of Appalachia qualify as a National Institute of Health designated health disparity population with high poverty, unemployment, and lack of access to health services (Krometis et al., 2017; Mamudu et al., 2017; Robinson, 2015; Shah, 2020; Zullig and Hendryx, 2011). The prevalence of chronic diseases in these Appalachian counties is generally higher than those of the respective states and the nation (Leukefeld et al., 2007; Shah, 2020; Zullig and Hendryx, 2011). During 2017 and 2020, the PCORI project was undertaken and it involved an extensive range of data collection, spanning environmental scans to surveys and focus group discussions. An integral part of the PCORI project was extensive community engagement, which culminated in a network of CVD stakeholders comprising patients/family, non-licensed caregivers, providers/professionals, and community leaders from across the Central Appalachian region. With the increasing evidence that patients with chronic diseases such as CVD are at higher risk for hospitalization and fatalities due to COVID-19 (Dhakal et al., 2020; Li et al., 2020) these CVD stakeholders were invited to complete a 20-item questionnaire REDCap survey during March and April 2020 to ascertain information on their lived experience pertaining to adherence to prevention and mitigation strategies. A total of 102 CVD stakeholders from across Appalachian counties in the six states [KY, NC, OH, TN, VA, and WV] responded to the survey and were included in this study.

\section{Study variables}

Outcomes. Perception of risk was the primary outcome, as measured by three independent models including (1) perception of risk for one's self, (2) perception of risk for one's family/friends, and (3) perception of risk for one's community. Perception of risk (self) was based on the question 'What threat does COVID-19 pose to you?' Perception of risk (family/friends) was based on the question 'What threat does COVID-19 pose to your family/ friends?' Perception of risk (community) was based on 'What 
threat does COVID-19 pose to your community?' For each perceived risk survey question, participants answered none, low, moderate, or high, and responses were coded as ordinal numbers $0-3$ in the order of severity, with 0 representing none, and 3 representing high.

Independent variables. Actual risk was derived as a risk score based on the number of chronic conditions ( 0 none; 5 maximum) reported for each participant. The conditions assessed include cancer, chronic obstructive pulmonary disease (COPD), diabetes, heart disease, and hypertension.

Controls in the models include age, sex, education, employment status, and health insurance status. Education, employment ( 1 =employed, $0=$ unemployed), health insurance and sex ( $1=$ male, $0=$ female) were coded as binary variables. Education was categorized based on high school or less education. Health insurance was coded with 1 representing no insurance, and 0 indicating participants had a current health insurance plan (private or public). Age was included in the model as a continuous variable.

Data analysis. The analyses were conducted using SAS version 9.2 (SAS Institute, Inc., Cary, NC, USA). Tetrachoric correlations did not indicate collinearity problems (all correlations $<0.75$; results available on request). In addition to descriptive statistics, three separate models were used to assess the association between actual risk and perceived risk (outcome). Generalized linear models (GLM) were used to assess actual risk) to estimate changes in perceived risk to self, family/friends, and community. Each GLM model was adjusted for age, sex, employment status, insurance status, and education.

\section{Results}

Characteristics of the study population. Descriptive characteristics are presented in Table 1 . The mean age of the survey participants was $54.6 \pm 13.9$ years and $68.6 \%$ of the participants were female. There were $35.3 \%$ of the participants reported no current employment, $10.8 \%$ reported not having health insurance, and $12.7 \%$ reported having a high school education or less. Overall, $54.9 \%$ of the participants reported having at least one chronic disease, while $21.6 \%$ were burdened with two or more chronic diseases. Prevalence of chronic disease was highest for hypertension $(42.2 \%)$, followed by heart disease $(16.7 \%)$, and diabetes $(9.8 \%)$.

Actual risk and perceptions of risk for COVID-19. Results of the GLM models are reported in Tables 2-4. Actual risk $(b=0.24 ; p=0.04)$ was positively associated with perception of risk (self) (Table 2). Not having health insurance $(b=-0.59$; $p=0.04)$ and male sex $(b=-0.45 ; p=0.02)$ were associated with perception of risk (self) in the negative direction. There was no significant association reported between actual risk $(p=0.68)$ and perception of risk (family/friends) (Table 3 ). Not having health insurance $(b=-0.92 ; p<0.001)$ and male sex $(b=-0.47$; $p=0.01)$ were associated with perception of risk (self) in the negative direction. There was no significant association between actual risk and perceived risk for one's community $(p=0.11)$, however, a significant negative association was found with high school education or less $(b=-0.55 ; p=0.02)$ (Table 4$)$.

\section{Discussion}

The rapid evolution of the COVID-19 pandemic and the prevention and mitigation measures that have been implemented create a perception that the health system is failing to protect individuals against the spread of the virus (Van den Broucke,
Table 1 Descriptive characteristics of the sample $(N=102)$.

\begin{tabular}{lc} 
Variable & $(\boldsymbol{n}, \boldsymbol{\%})$ \\
\hline Age (mean, SD) & $54.6(13.9)$ \\
Gender & \\
Male & $32(31.4)$ \\
Female & $70(68.6)$ \\
Educational status & \\
High school/GED or less & $13(12.7)$ \\
Some college & $14(13.7)$ \\
Associates degree or higher & $75(73.6)$ \\
Current employed & \\
Yes & $66(64.7)$ \\
No & $36(35.4)$ \\
Chronic disease & \\
Cancer & $6(5.9)$ \\
COPD & $4(3.9)$ \\
Diabetes & $10(9.8)$ \\
Heart Disease & $17(16.7)$ \\
Hypertension & $43(42.2)$ \\
Number of chronic conditions & \\
Two or more & $22(21.6)$ \\
One & $34(33.3)$ \\
None & $46(45.1)$ \\
Perception of threat to self & \\
High & $26(25.5)$ \\
Moderate & $38(37.3)$ \\
Low & $33(32.4)$ \\
None & $5(4.9)$ \\
Perception of threat to family/friends & \\
High & $44(43.1)$ \\
Moderate & $34(33.3)$ \\
Low & $19(18.6)$ \\
None & $5(4.9)$ \\
Perception of threat to community & \\
High & $47(46.1)$ \\
Moderate & $39(38.2)$ \\
Low & $13(12.8)$ \\
None & $3(3.0)$ \\
&
\end{tabular}

Table 2 Generalized linear models predicting the association between perception of risk of COVID-19 to one's self.

\begin{tabular}{lrll} 
& \multicolumn{1}{l}{ b } & SE & p \\
\hline Intercept & 1.48 & 0.37 & $0 . \mathbf{0 1}$ \\
Actual risk & & 0.11 & $\mathbf{0 . 0 4}$ \\
Employment status: Not & -0.10 & 0.17 & 0.61 \\
employed & & & \\
Education: High school/GED & -0.07 & 0.27 & 0.79 \\
or less & & & \\
Health insurance: None & -0.59 & 0.27 & $\mathbf{0 . 0 4}$ \\
Gender (male) & -0.45 & 0.19 & $\mathbf{0 . 0 2}$ \\
Age & 0.02 & 0.01 & 0.32
\end{tabular}

aBased on a number of chronic conditions including cancer, COPD, heart disease, hypertension, and diabetes. Statistically significant values $(p<.05)$ are marked in bold.

2020). This generates a need for people to have greater control of their health and to protect themselves from adverse consequences. Given the increasing trend of positive COVID-19 tests and related hospitalization and fatalities, it is important to understand people's perceptions about the disease to inform short- to medium-term initiatives to prevent the spread of the disease and long-term initiatives to facilitate the uptake of COVID-19 vaccination. Coordination of public health messages regarding risks and interpretation of the messages received is critical during a pandemic (Smith and Judd, 2020). Globally, 


\begin{tabular}{|c|c|c|c|}
\hline & $\boldsymbol{b}$ & SE & $p$ \\
\hline Intercept & 2.18 & 0.38 & $<0.001$ \\
\hline Actual riska & 0.05 & 0.11 & 0.68 \\
\hline $\begin{array}{l}\text { Employment status: Not } \\
\text { employed }\end{array}$ & -0.23 & 0.21 & 0.28 \\
\hline $\begin{array}{l}\text { Education: High school/GED } \\
\text { or less }\end{array}$ & 0.13 & 0.47 & 0.65 \\
\hline Health insurance: None & -0.92 & 0.28 & $<0.001$ \\
\hline Gender (male) & -0.47 & 0.17 & 0.01 \\
\hline Age & 0.01 & 0.01 & 0.53 \\
\hline
\end{tabular}

aBased on number of chronic conditions including cancer, COPD, heart disease, hypertension, and diabetes. Statistically significant values $(p<.05)$ are marked in bold.

\begin{tabular}{|c|c|c|c|}
\hline & $\boldsymbol{b}$ & SE & $p$ \\
\hline Intercept & 2.59 & 0.33 & $<0.001$ \\
\hline Actual riska & -0.14 & 0.10 & 0.16 \\
\hline $\begin{array}{l}\text { Employment status: Not } \\
\text { employed }\end{array}$ & -0.16 & 0.19 & 0.39 \\
\hline $\begin{array}{l}\text { Education: High school/GED } \\
\text { or less }\end{array}$ & -0.55 & 0.24 & 0.02 \\
\hline Health insurance: none & -0.45 & 0.25 & 0.07 \\
\hline Gender (Male) & -0.13 & 0.17 & 0.43 \\
\hline Age & 0.01 & 0.01 & 0.97 \\
\hline
\end{tabular}

approximately 1.7 billion (22\%) of the world's population have at least one underlying condition that predisposes them to increased risk of a severe form of COVID-19-related health consequences and 350 million (4\%) are at risk for hospitalization (Clark et al., 2020). Individuals with CVD, chronic kidney disease, diabetes, chronic respiratory disease, and a range of other chronic conditions are at an increased risk of requiring in-hospital treatment such as oxygen supplementation (Clark et al., 2020). Identifying at-risk populations is important for making projections of the probable health burden and for the design of effective strategies to reduce the risk of transmission to highly vulnerable groups (Clark et al., 2020).

In the case of COVID-19, it is highly important to understand the disparity between perceived risk and actual risk. Perceiving the risk as high may decrease one's likelihood of engaging in risky behaviors, such as attending social gatherings, avoidance of hand-washing, avoidance of face coverings (Tran and Ravaud, 2020). Overall, the prevalence of elevated perceived risk to one's self was high, with $62.8 \%$ of the participants reporting moderate or high levels of risk. Factors such as age (mean age of 54), and high vulnerability to chronic disease, may further explain the high perceived risk of COVID-19 to one's self in this study population. Furthermore, as individuals age, there may be less control of one's health, as one may be burdened with a chronic disease that is not reversible. Thus, people who believe they can control their health may also believe they are less susceptible to disease, (Hamilton and Lobel, 2015) such as COVID-19.

Our study found that there is a positive correlation between one's actual COVID-19 risk, which is their own disease burden, and their perception of risk for themselves. As chronic diseases contribute significantly to the global burden of disease worldwide (Lozano et al., 2012) these findings further reinforce the perception of risk individuals with chronic disease would face. Understanding risk perception about COVID-19 may help understand the public attitudes toward the disease and predict behaviors (He et al., 2020). Given that those with chronic disease are at increased risk of COVID-19 related hospitalization and mortality, they are highly vulnerable and may explain the association with their perception of risk (self) (Xia et al., 2020).

Beyond the perception of risk of COVID-19 to one's self, one's actual risk was not associated with one's perception of risk for one's family/friends or community. While one may be concerned about the impact on their family/friends or community, the study found no direct connection between these factors and one's own actual risk. However, COVID-19 may pose threats to the wellbeing of children and families in other ways, as these may be attributed to challenges related to social disruption such as financial insecurity, caregiving burden, and confinement-related stress (Prime et al., 2020). Other challenges not measured in the study, such as mental health/well-being (Yuan et al., 2020), school closures, unemployment, business closures, and other factors pose a substantial threat to the well-being of one's family/friends as well as their community (Parolin, 2020; Prime et al., 2020). The study also found that not having health insurance significantly reduced one's perception of threat to themselves or their family/ friends. This finding may be consistent with assertions that individuals who have health insurance may be more likely to have higher health literacy, may value their health more, and be more risk aversive (Baicker et al., 2015; Barnes and Hanoch, 2017; Outreville, 2013). The study additionally found that the male gender predicted lower perceived risk for one's self and family/ friends. This finding is consistent with prior findings that men are less risk aversive when referring to their health than women (Bolhaar et al., 2012; Franks et al., 1996; Warshawsky-Livne et al., 2014; Zheng et al., 2020). Overall, these findings are important, given the disproportionate level of COVID-19 impact in rural, underserved areas (Karim andand Chen, 2020; Tan et al., 2020).

Strengths and limitations. The study findings should be interpreted with certain limitations. These results may not be generalizable to the population-at-large as a regional sample from Central Appalachia was used. The demographic of the sample was of higher socioeconomic status in comparison to the general population in Central Appalachia. This was clearly seen based on the higher education and employment rates in comparison to regional estimates. Another limitation is that study constructs were self-reported, so there is a chance of recall bias, and the severity of chronic disease was not captured in the study. For example, hypertension may have a broad range of systolic or diastolic readings that are classified as a diagnosis. Future studies are needed considering more detailed information regarding the severity and duration of chronic disease to more precisely measure actual risk. In light of these limitations, the current study informs us of the importance of directing targeted interventions for those who are at higher risks. This includes increased knowledge about COVID-19 prevention and the importance of compliance with recommended guidelines. As the perceived risk to one's self is associated with one's actual risk, it is highly critical to focus on those who are at increased risk, particularly among those burdened with chronic disease.

\section{Conclusions}

Individuals' actual risk was positively associated with the perception of risk of COVID-19 to themselves; however, this was not 
true when evaluated for family/friends or the community. This indicates that one's perception of risk for COVID-19 is greater for their own health compared to their family/friends or the community. Monitoring and follow-up with patients suffering from chronic diseases and addressing their lack of awareness of risk to others is needed to prevent and curtail the spread of COVID-19. Therefore, culturally relevant health education is imperative in rural areas, such as Central Appalachia. Providers, public health professionals and other key stakeholders must raise awareness of individuals at high risk for poor COVID-19 outcomes such as those burdened with chronic diseases, their family members, and members of communities with higher rates of health illiteracy.

\section{Data availability}

The data pertaining to this study are available from the corresponding author upon request.

Received: 13 January 2021; Accepted: 21 September 2021; Published online: 07 October 2021

\section{References}

Barnes AJ, Hanoch Y (2017) Knowledge and understanding of health insurance: challenges and remedies. Israel J Health Policy Res. https://doi.org/10.1186/ s13584-017-0163-2

Bauer UE, Briss PA, Goodman RA, Bowman BA (2014) Prevention of chronic disease in the 21st century: elimination of the leading preventable causes of premature death and disability in the USA. The Lancet. https://doi.org/ 10.1016/S0140-6736(14)60648-6

Bavel JJV, Baicker K, Boggio PS, Capraro V, Cichocka A, Cikara M, Crockett MJ, Crum AJ, Douglas KM, Druckman JN, Drury J, Dube O, Ellemers N, Finkel EJ, Fowler JH, Gelfand M, Han S, Haslam SA, Jetten J, ... Willer R (2020) Using social and behavioural science to support COVID-19 pandemic response. Nat Hum Behav. https://doi.org/10.1038/s41562-020-0884-z

Bhatraju PK, Ghassemieh BJ, Nichols M, Kim R, Jerome KR, Nalla AK, Greninger AL, Pipavath S, Wurfel MM, Evans L, Kritek PA, West TE, Luks A, Gerbino A, Dale CR, Goldman JD, O'Mahony S, Mikacenic C (2020) COVID-19 in critically ill patients in the Seattle region-case series. New Engl J Med. https://doi.org/10.1056/NEJMoa2004500

Bish A, Michie S (2010) Demographic and attitudinal determinants of protective behaviours during a pandemic: a review. Br J Health Psychol. https://doi.org/ 10.1348/135910710X485826

Bolhaar J, Lindeboom M, Van der Klaauw B (2012) A dynamic analysis of the demand for health insurance and health care. Eur Econ Rev. https://doi.org/ 10.1016/j.euroecorev.2012.03.002

Bruine de Bruin W, Bennett D (2020) Relationships between initial COVID-19 risk perceptions and protective health behaviors: a National Survey. Am J Prev Med. https://doi.org/10.1016/j.amepre.2020.05.001

Clark A, Jit M, Warren-Gash C, Guthrie B, Wang HHX, Mercer SW, Sanderson C, McKee M, Troeger C, Ong KL, Checchi F, Perel P, Joseph S, Gibbs HP, Banerjee A, Eggo RM, Nightingale ES, O'Reilly K, Jombart T, ... Jarvis CI (2020) Global, regional, and national estimates of the population at increased risk of severe COVID-19 due to underlying health conditions in 2020: a modelling study. Lancet Global Health. https://doi.org/10.1016/s2214$109 \mathrm{x}(20) 30264-3$

Courtemanche C, Garuccio J, Le A, Pinkston J, Yelowitz A (2020) Strong social distancing measures in the united states reduced the covid-19 growth rate. Health Aff. 39(7). https://doi.org/10.1377/hlthaff.2020.00608

Dhakal BP, Sweitzer NK, Indik JH, Acharya D, William P (2020) SARS-CoV-2 infection and cardiovascular disease: COVID-19 heart. Heart Lung Circ. https://doi.org/10.1016/j.hlc.2020.05.101

Ding Y, Du X, Li Q, Zhang M, Zhang Q, Tan X, Liu Q (2020) Risk perception of coronavirus disease 2019 (COVID-19) and its related factors among college students in China during quarantine. PLoS ONE https://doi.org/10.1371/ journal.pone.0237626

Dryhurst S, Schneider CR, Kerr J, Freeman ALJ, Recchia G, van der Bles AM, Spiegelhalter D, van der Linden S (2020) Risk perceptions of COVID-19 around the world. J Risk Res. https://doi.org/10.1080/13669877.2020.1758193

Encyclopedia of Behavioral Medicine (2013) Encycl Behav Med https://doi.org/ 10.1007/978-1-4419-1005-9

Fischhoff B (1995) Risk perception and communication unplugged: twenty years of process. Risk Anal. https://doi.org/10.1111/j.1539-6924.1995.tb00308.x
Franks P, Gold MR, Clancy CM (1996) Use of care and subsequent mortality: the importance of gender. Health Services Research.

Golestaneh L, Neugarten J, Fisher M, Billett HH, Gil MR, Johns T, Yunes M, Mokrzycki MH, Coco M, Norris KC, Perez HR, Scott S, Kim RS, Bellin E (2020) The association of race and COVID-19 mortality. EClinicalMedicine 000:100455. https://doi.org/10.1016/j.eclinm.2020.100455

Guan WJ, Liang WH, He JX, Zhong NS (2020a) Cardiovascular comorbidity and its impact on patients with COVID-19. Eur Respir J. 55(6). https://doi.org/ 10.1183/13993003.01227-2020

Guan WJ, Liang WH, Zhao Y, Liang HR, Chen ZS, Li YM, Liu XQ, Chen RC, Tang CL, Wang T, Ou CQ, Li L, Chen PY, Sang L, Wang W, Li JF, Li CC, Ou LM Cheng B, ... He JX (2020b) Comorbidity and its impact on 1,590 patients with Covid-19 in China: a nationwide analysis. Eur Respir J. https://doi.org/ 10.1183/13993003.00547-2020

Hamilton JG, Lobel M (2015) Psychosocial factors associated with risk perceptions for chronic diseases in younger and middle-aged women. Women Health. https://doi.org/10.1080/03630242.2015.1061094

He S, Chen S, Kong L, Liu W (2020) Analysis of risk perceptions and related factors concerning COVID-19 epidemic in Chongqing, China. J Community Health https://doi.org/10.1007/s10900-020-00870-4

Ibuka Y, Chapman GB, Meyers LA, Li M, Galvani AP (2010) The dynamics of risk perceptions and precautionary behavior in response to 2009 (H1N1) pandemic influenza. BMC Infect Dis. https://doi.org/10.1186/1471-2334-10-296

Iorfa SK, Ottu IFA, Oguntayo R, Ayandele O, Kolawole SO, Gandi JC, Dangiwa AL, Olapegba PO (2020) COVID-19 knowledge, risk perception, and precautionary behavior among nigerians: a moderated mediation approach Front Psychol 11 https://doi.org/10.3389/fpsyg.2020.566773

Irigoyen-Camacho ME, Velazquez-Alva MC, Zepeda-Zepeda MA, Cabrer-Rosales MF, Lazarevich I, Castaño-Seiquer A (2020) Effect of income level and perception of susceptibility and severity of covid-19 on stay-at-home preventive behavior in a group of older adults in Mexico City. Int J Environ Res Public Health 17(20) https://doi.org/10.3390/ijerph17207418

Jehi L, Ji X, Milinovich A, Erzurum S, Rubin B, Gordon S, Young J, Kattan MW (2020) Individualizing risk prediction for positive COVID-19 testing: results from 11,672 patients. Chest. https://doi.org/10.1016/j.chest.2020.05.580

Karim SA, Chen H (2020) Deaths from COVID-19 in rural, micropolitan, and metropolitan areas: a county-level comparison. J Rural Health. https:// doi.org/10.1111/jrh.12533

Karlsson LC, Soveri A, Lewandowsky S, Karlsson L, Karlsson H, Nolvi S, Karukivi M, Lindfelt M, Antfolk J (2021) Fearing the disease or the vaccine: the case of COVID-19. Personal Individ Differ 172. https://doi.org/10.1016/ j.paid.2020.110590

Krometis LA, Gohlke J, Kolivras K, Satterwhite E, Marmagas SW, Marr LC (2017) Environmental health disparities in the Central Appalachian region of the United States. Rev Environ Health. https://doi.org/10.1515/reveh-2017-0012

Leukefeld C, Walker R, Havens J, Leedham CA, Tolbert V (2007) What does the community say: key informant perceptions of rural prescription drug use. J Drug Issues. https://doi.org/10.1177/002204260703700302

Li J, Guo T, Dong D, Zhang X, Chen X, Feng Y, Wei B, Zhang W, Zhao M, Wan J (2020) Defining heart disease risk for death in COVID-19 infection. QJM https://doi.org/10.1093/qjmed/hcaa246

Lohan V, Singh RP (2019) Home automation using internet of things. Lect Notes Netw Syst. https://doi.org/10.1007/978-981-13-0277-0_24

Lozano R, Naghavi M, Foreman K, Lim S, Shibuya K, Aboyans V, Abraham J, Adair T, Aggarwal R, Ahn SY, AlMazroa MA, Alvarado M, Anderson HR, Anderson LM, Andrews KG, Atkinson C, Baddour LM, Barker-Collo S, Bartels DH, ... Murray CJL (2012) Global and regional mortality from 235 causes of death for 20 age groups in 1990 and 2010: a systematic analysis for the Global Burden of Disease Study 2010. The Lancet. https://doi.org/ 10.1016/S0140-6736(12)61728-0

Mamudu HM, Paul TK, Wang L, Veeranki SP, Panchal HB, Alamian A, Budoff M (2017) Association between multiple modifiable risk factors of cardiovascular disease and hypertension among asymptomatic patients in central appalachia. South Med J https://doi.org/10.14423/SMJ.0000000000000602

Meacham SL, Sukpraprut S, Goessl C, Stevens W, Meisha D (2015) Prevalence rates of adult obesity and environmental factors impacting health in coal producing and non-coal producing appalachian counties in Southwest Virginia. In: J.C. Craynon (ed.) Proceedings of the 2nd environmental considerations in energy production conference.

Nande A, Adlam B, Sheen, J, Levy, MZ, \& Hill, AL (2021) Dynamics of COVID-19 under social distancing measures are driven by transmission network structure. PLoS Comput Biol 17(2). https://doi.org/10.1371/ JOURNAL.PCBI.1008684

O'Brien WH, Wang S, Xu H, Wang S, Yang Z, Yang JT, Liu Q, Zhang X, Tang L, Varga AV, Sims T, Lim CX, Jarukasemthawee S, Pisitsungkagarn K (2021) Psychological reactions to COVID-19: Survey data assessing perceived susceptibility, distress, mindfulness, and preventive health behaviors. Data Brief 34. https://doi.org/10.1016/j.dib.2020.106687 
Outreville JF (2013) Risk aversion, risk behavior and demand for insurance: a survey. SSRN Electron J. https://doi.org/10.2139/ssrn.2363877

Parolin Z (2020) Unemployment and child health during COVID-19 in the USA. The Lancet Public Health. https://doi.org/10.1016/S2468-2667(20)30207-3

Prime H, Wade M, Browne DT (2020) Risk and resilience in family well-being during the COVID-19 pandemic. Am Psychol. https://doi.org/10.1037/amp0000660

Robinson C (2015) An exploration of poverty in Central Appalachia: questions of culture, industry, and technology. KOME https://doi.org/10.17646/ KOME.2015.26

Sandman PM (1989) Hazard versus outrage in the public perception of risk. Eff Risk Commun https://doi.org/10.1007/978-1-4613-1569-8_6

Schmälzle R, Renner B, Schupp HT (2017) Health risk perception and risk communication. Policy Insights Behav Brain Sci https://doi.org/10.1177/ 2372732217720223

Shah DT (2020) The COVID-19 crisis: how rural Appalachia is handling the pandemic? Marshall J Med. https://doi.org/10.33470/2379-9536.1287

Shahin MAH, Hussien RM (2020) Risk perception regarding the COVID-19 outbreak among the general population: a comparative Middle East survey. Middle East Curr Psychiatry. 27(1). https://doi.org/10.1186/s43045-020-00080-7

Shi R, Meacham S, Davis GC, You W, Sun Y, Goessl C (2019) Factors influencing high respiratory mortality in coal-mining counties: a repeated cross-sectional study. BMC Public Health. https://doi.org/10.1186/s12889-019-7858-y

Smith JA, Judd J (2020) COVID-19: vulnerability and the power of privilege in a pandemic. Health Promot J Aust. https://doi.org/10.1002/hpja.333

Tan TQ, Kullar R, Swartz TH, Mathew TA, Piggott DA, Berthaud V (2020) Location matters: geographic disparities and impact of coronavirus disease 2019. J Infect Dis https://doi.org/10.1093/infdis/jiaa583

The Lancet (2020) Emerging understandings of 2019-nCoV. The Lancet https:// doi.org/10.1016/S0140-6736(20)30186-0

Tian S, Hu N, Lou J., Chen K, Kang X, Xiang Z, Chen H, Wang D, Liu N, Liu D, Chen G, Zhang Y, Li D, Li J, Lian H, Niu S, Zhang L, Zhang J (2020) Characteristics of COVID-19 infection in Beijing. J Infect https://doi.org/ 10.1016/j.jinf.2020.02.018

Tran VTVT, Ravaud P (2020) COVID-19 related perceptions, context and attitudes of adults with chronic conditions: Results from a cross-sectional survey nested in the ComPaRe e-cohort. PLoS ONE https://doi.org/10.1371/journal.pone.0237296

Van den Broucke S (2020) Why health promotion matters to the COVID-19 pandemic, and vice versa. Health Promot Int. https://doi.org/10.1093/heapro/ daaa042

Van Der Weerd W, Timmermans DRM, Beaujean DJMA, Oudhoff J, Van Steenbergen JE (2011) Monitoring the level of government trust, risk perception and intention of the general public to adopt protective measures during the influenza A (H1N1) pandemic in the Netherlands. BMC Public Health https://doi.org/10.1186/1471-2458-11-575

Warshawsky-Livne L, Novack L, Rosen AB, Downs SM, Shkolnik-Inbar J, Pliskin JS (2014) Gender differences in risk attitudes. Adv Health Econ Health Serv Res https://doi.org/10.1108/S0731-219920140000024003

Weinberger DM, Chen J, Cohen T, Crawford FW, Mostashari F, Olson D, Pitzer VE, Reich NG, Russi M, Simonsen L, Watkins A, Viboud C (2020) Estimation of excess deaths associated with the COVID-19 pandemic in the United States, March to May 2020. JAMA Intern Med. https://doi.org/10.1001/ jamainternmed.2020.3391

Xia Y, Li Q, Li W, Shen H (2020) Elevated mortality of chronic diseases during COVID-19 pandemic: a cause for concern? Ther Adv Chron Dis. https:// doi.org/10.1177/2040622320961590

Yang X, Yu Y, Xu J, Shu H, Xia J, Liu H, Wu Y, Zhang L, Yu Z, Fang M, Yu T, Wang Y, Pan S, Zou X, Yuan S, Shang Y (2020) Clinical course and outcomes of critically ill patients with SARS-CoV-2 pneumonia in Wuhan, China: a single-centered, retrospective, observational study. Lancet Respir Med. https://doi.org/10.1016/S2213-2600(20)30079-5

Yuan X, Mu JS, Mo GX, Hu XS, Yan P, Xie LX (2020) Respiratory support for severe 2019-nCoV pneumonia suffering from acute respiratory failure: time and strategy. Chin J Tuberc Respir Dis 43(3):E010. https://doi.org/10.3760/ cma.j.issn.1001-0939.2020.0010.

Zheng Y, Vukina T, Zheng X (2020) Risk aversion, moral hazard, and gender differences in health care utilization. GENEVA Risk Insur Rev. https:// doi.org/10.1057/s10713-020-00048-x

Zhong Y, Liu W, Lee TY, Zhao H, Ji J (2020) Risk perception, knowledge, information sources and emotional states among COVID-19 patients in Wuhan, China. Nurs Outlook https://doi.org/10.1016/j.outlook.2020.08.005

Zullig KJ, Hendryx M (2011) Health-related quality of life among central appalachian residents in mountaintop mining counties. Am J Public Health https://doi.org/10.2105/AJPH.2010.300073

\section{Acknowledgements}

This study was funded by the Patient Center Outcomes Research Institute (PCORI): Developing a Research Agenda to Prevent and Control CVD in Central Appalachia (PI: Mamudu HM).

\section{Author contributions}

MA (Ahuja), HM, FW, and DS substantially conceptualized and designed the study. MA (Ahuja) and KD wrote the draft manuscript. HM, TP, MA (Awasthi) collected data. MA (Ahuja) conducted data analysis. All authors commented on and approved the submitted manuscript.

\section{Competing interests}

The authors declare no competing interests.

\section{Ethical approval}

The research is part of an East Tennessee State University Institutional Review Board PCORI approved protocol that embodies the protection of human subjects.

\section{Informed consent}

The research is part of an East Tennessee State University Institutional Review Board PCORI approved protocol that embodies informed consent.

\section{Additional information}

Correspondence and requests for materials should be addressed to Manik Ahuja.

Reprints and permission information is available at http://www.nature.com/reprints

Publisher's note Springer Nature remains neutral with regard to jurisdictional claims in published maps and institutional affiliations.

Open Access This article is licensed under a Creative Commons Attribution 4.0 International License, which permits use, sharing, adaptation, distribution and reproduction in any medium or format, as long as you give appropriate credit to the original author(s) and the source, provide a link to the Creative Commons license, and indicate if changes were made. The images or other third party material in this article are included in the article's Creative Commons license, unless indicated otherwise in a credit line to the material. If material is not included in the article's Creative Commons license and your intended use is not permitted by statutory regulation or exceeds the permitted use, you will need to obtain permission directly from the copyright holder. To view a copy of this license, visit http://creativecommons.org/ licenses/by/4.0/

(c) The Author(s) 2021, corrected publication 2021 